\title{
Recommendations for the repair, the lining or the strengthening of concrete slabs or pavements with bonded cement-based material overlays
}

Recommandations pour la réparation, le re-surfaçage ou le renforcement des dallages industriels ou des chaussées en béton par un rechargement adhérent à base cimentaire

B. Bissonnette

Laval University, Canada

L. Courard

University of Liège, Belgium

H. Beushausen

University of Cape Town, South Africa

D. Fowler, M. Trevino

The University of Texas at Austin, USA

A. Vaysburd

Vaycon Consulting, U.S.A

\begin{abstract}
The recommendations presented in this publication are inspired by the State of the Art Report edited by the RILEM technical committee TC 193 RLS Bonded cement-based material overlays for the repair, the lining or the strengthening of slabs and pavements. The objective is to lay out all the practical aspects to be considered in the design of concrete overlays: bonded concrete overlay process, assessment of the existing structure, surface preparation, overlay materials, design methods, construction procedure and quality control/assurance (QC/QA) system, and maintenance.
\end{abstract}

Keywords: bond, concrete, overlay, repair, strengthening

\section{Résumé}

Ces recommandations s'inspirent de l'état de l'art issu des travaux du Comité Technique RILEM TC 193 RLS Réparation, re-surfaçage ou renforcement des dallages industriels ou des chaussées par un rechargement adhérent à base cimentaire. Elles visent à donner aux chercheurs, ingénieurs et auteurs de projets les données fondamentales à prendre en considération lors de l'élaboration d'un projet de resurfaçage : processus de décision, 
évaluation de la structure existante, préparation de la surface, matériaux de resurfaçage, conception, construction, contrôle qualité et entretien.

\section{INTRODUCTION}

Concrete has now been used for more than a century and today, countless structures around the world are either in need for repair to restore their original characteristics or strengthening to withstand ever-increasing loads. The bonded overlay technique is particularly suitable in the case of structures with large surface areas such as slabs and pavements.

The 193-RLS RILEM Technical Committee was created in September 2001 in order to put together a state-of-the-art and issue technical recommendations to achieve durable bonded overlays (for repair or strengthening). A review of the state of knowledge and practice was first conducted in order to provide a thorough understanding of all relevant aspects involved in the achievement of durable overlays, from the design stage to the maintenance [1]. This effort ultimately led to the identification of general practical Recommendations, which are provided in this paper.

The Recommendations document is a guiding tool resulting from a consensus among the TC members and is intended not only for practitioners, but also for anyone involved in the design, construction, maintenance or management of concrete slabs and pavements. All practical aspects of concrete slab overlaying are addressed: bonded concrete overlay process, assessment of the existing structure, surface preparation, overlay materials, design methods, construction procedure and quality control/assurance (QC/QA) system, and maintenance.

\section{SCOPE AND DECISION PROCESS}

\subsection{Purpose of Overlays}

The purpose of bonded concrete overlays, used since 1909, is to extend the life of a concrete slab, pavement, bridge deck or other structural slab. The additional thickness of the bonded overlay can provide a significant increase in stiffness that will reduce the flexural stresses. Other reasons for using bonded overlays include:

1. increasing the frictional resistance or providing a smooth surface, 
2. increasing the elevation to match an adjacent slab,

3. provide a more durable wearing surface or to repair a damaged slab and

4. provide architectural features such as color or texture.

\subsection{The Bonded Concrete Overlay (BCO) Process}

The BCO process involves:

1. project selection,

2. design,

3. construction, and

4. quality assurance.

The project selection can be summarized by the flow chart (Fig. 1):

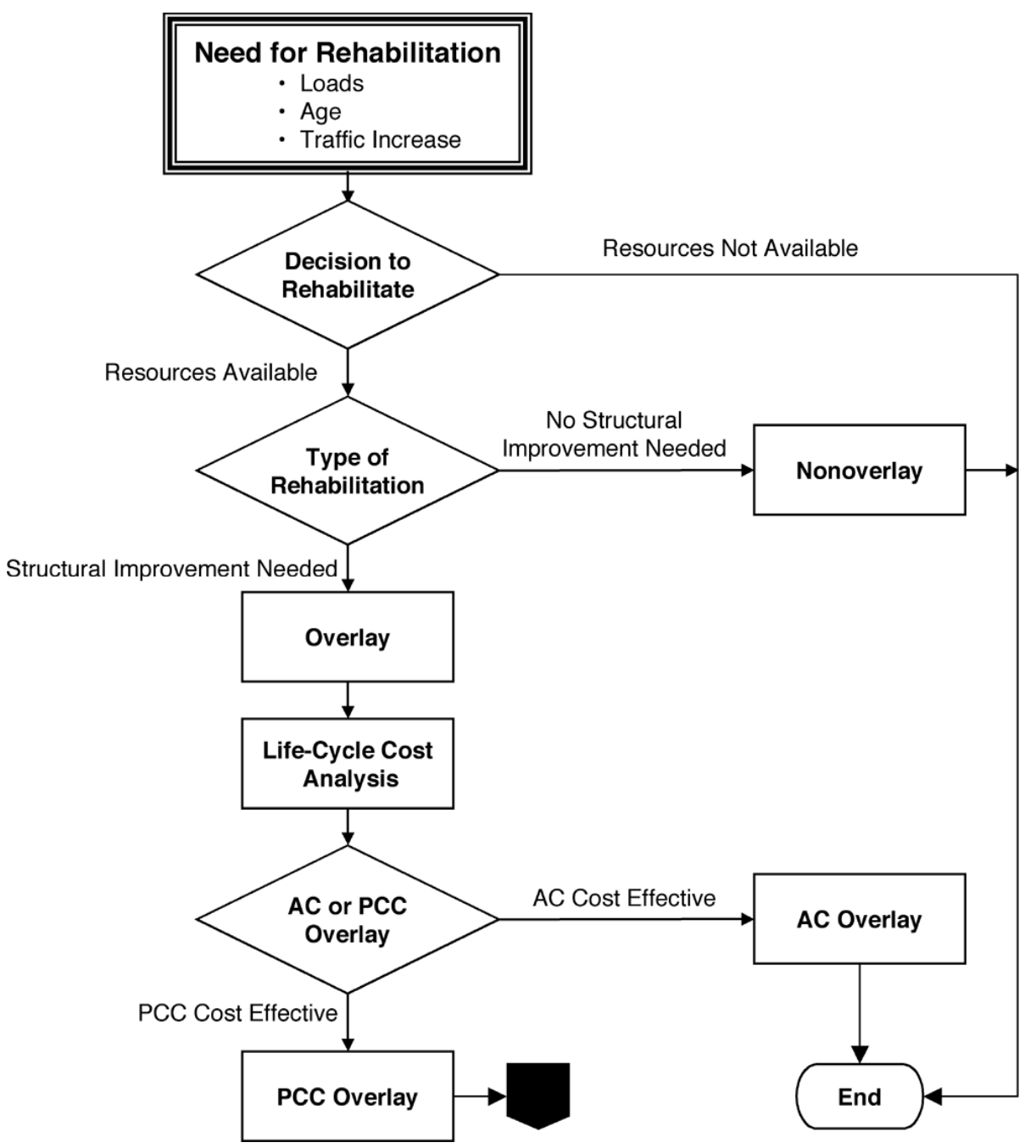




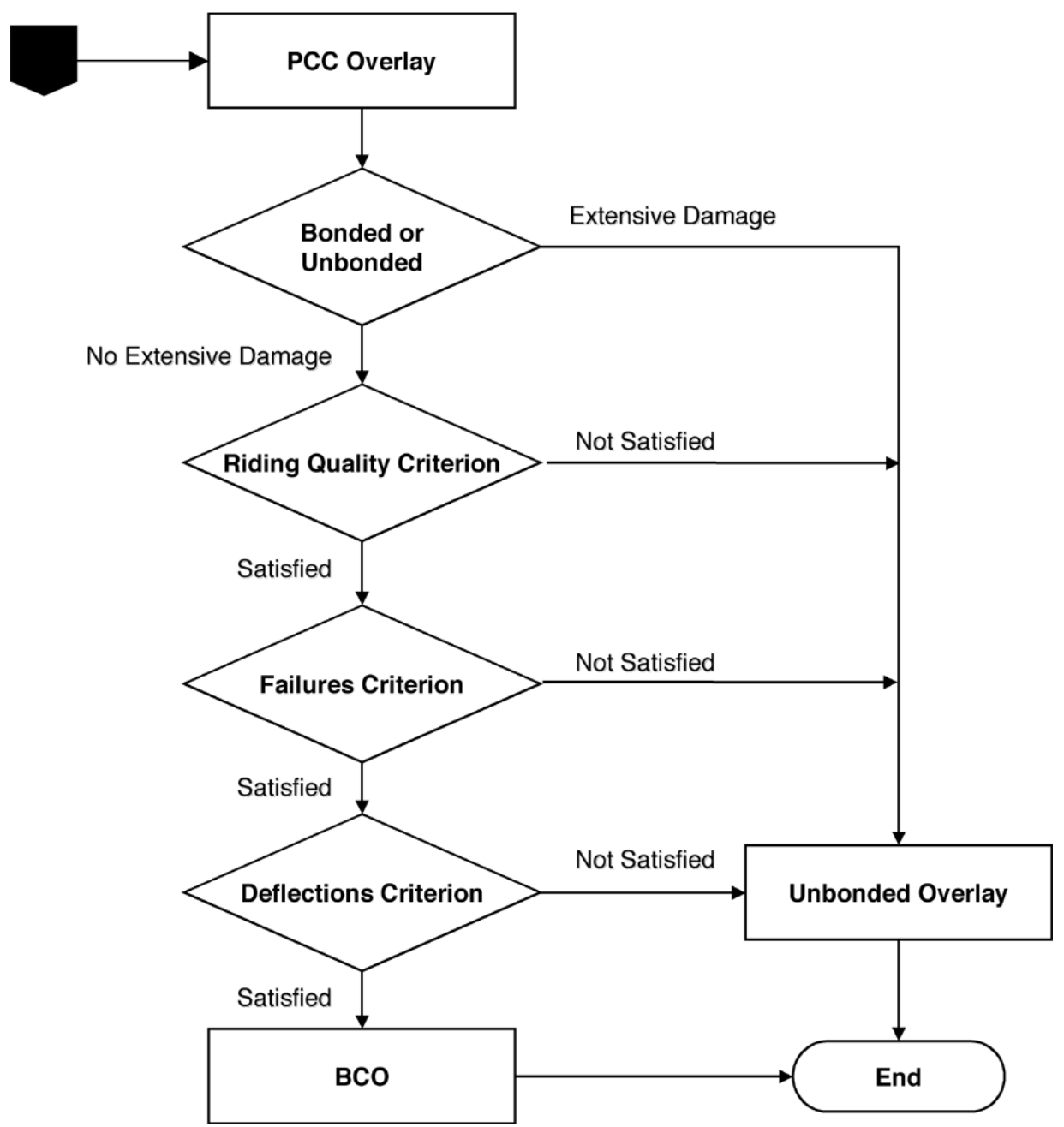

Fig. 1 Bonded Concrete Overlay Process (PCC for Portland Cement Concrete and AC for Asphalt Concrete)

The design decisions include the overlay design life, the traffic intensity, the remaining life of the original slab and the condition of the original slab. The thickness of the overlay is a function of structural capacity of the original pavement and the capacity of the bonded overlay.

The construction-related considerations are related to compatibility between overlay and original slab, repairs to the original slab that must be made, surface preparation and environmental conditions.

Finally, a comprehensive QA/QC program is required to insure that the $\mathrm{BCO}$ meets the user requirements.

\section{ASSESSMENT OF THE EXISTING STRUCTURE}

Assessment of the existing structure has to be made in order to point out its defects and their causes but also to attest the ability of the concrete structure to perform its function. The objective(s) of the assessment are a good knowledge of concrete structure residual 
performances and the characterization of its constitutive materials. The general process of assessment must at least include:

- present condition of the existing concrete structure, including non-visible and potential defects,

- original design approach,

- environment, including exposure to contamination,

- conditions during construction (including climatic conditions),

- history of the concrete structure,

- conditions of use (e.g. loading), and

- requirements for the future use of the concrete structure.

Assessment may be undertaken in several stages. Three levels are generally proposed for inspection (Table 1):

Table 1 Level of inspection for concrete structures

\begin{tabular}{lcc}
\hline Level of inspection & Frequency & Type of inspection \\
\hline A & every year & visual check \\
B & every 3 years & visual inspection \\
C & every 6 years & close-up inspection \\
\hline
\end{tabular}

The purpose of a preliminary assessment stage is to advise on the immediate safety of the concrete structure, to give an informed opinion on the urgency of commissioning further surveys, protection or repairs, and to outline what testing should be done to establish the causes and likely extent of the defects. A typical visual investigation might involve the following activities:

- perform a walk-through visual inspection to become familiar with the structure; gather background documents and information on the design, construction, maintenance, and operation of the structure;

- plan the complete investigation;

- perform a detailed visual inspection, and

- perform any necessary sampling or in-place tests.

Depending on the conclusions of the visual inspection, further operations will then be conducted in order to:

- identify cause(s) of defects,

- establish the extent of defects,

- establish whether defects can be expected to spread to parts that are at present unaffected,

- assess the effect of defects on structural capacity and

- identify all locations where protection or repair may be needed.

The causes and type of defect have to be considered during close-up inspection. They include material deteriorations as well as structural dysfunction. Causes may include but are not limited to what is described in Table 2: 
Table 2 Potential causes of degradation of concrete structures

\begin{tabular}{|c|c|}
\hline Main causes & Main effects \\
\hline $\begin{array}{l}\text { Causes of defects due to inadequate } \\
\text { structural design }\end{array}$ & \\
\hline $\begin{array}{l}\text { Causes of defects due to inadequate } \\
\text { construction or materials }\end{array}$ & $\begin{array}{l}\text { - inadequate mix design, insufficient } \\
\text { mixing, insufficient compaction, } \\
\text { excess water in mix; } \\
\text { - insufficient cover; } \\
\text { - insufficient or defective } \\
\text { waterproofing; } \\
\text { - contamination, poor or reactive } \\
\text { aggregates; } \\
\text { - inadequate curing and excessive } \\
\text { - inaporation }\end{array}$ \\
\hline Causes of defects revealed during service & $\begin{array}{l}\text { foundation movement, impacted } \\
\text { movement joints, overloading } \\
\text { - impact damage, expansion forces } \\
\text { from fires }\end{array}$ \\
\hline External environment and agents & $\begin{array}{l}\text { - } \\
\text { pevere climation, atmospheric } \\
\text { aggressive chemicalde, carbon dioxide, } \\
\text { - erosion, aggressive groundwater, } \\
\text { seismic action } \\
\text { - stray electric currents }\end{array}$ \\
\hline
\end{tabular}

The results of the completed assessment are only valid at the time that the repair works are designed and carried out. The nature and causes of defects, including potential combinations of causes, should be identified and recorded. This will allow defining a repair strategy and selecting optimal repair technique and products (Fig. 2). 
Fig. 2 Concrete repair process and repair strategy [2]

Minimum series of investigation should include:

- carbonation depth;

- concrete cover (over steel reinforcement);

- steel corrosion level;

- concrete cohesion (superficial zone);

- compressive strength of concrete;

- chloride content, alkali content and sulphate content;

- remaining alkalinity $\left(\mathrm{Ca}(\mathrm{OH})_{2}\right.$ content);

- any other test suitable and useful for pathology interpretation.

Table 3 gives a "memory-help chart", developed in order to avoid forgetting the main characteristics and properties of concrete to be involved in diagnosis. Required values of results are presented to provide an idea of what should be expected but actual requirements might differ, depending on local applicable codes and practices.

Table 3 Summary of tests and observations for quality evaluation of concrete according to EN 1504-10 [3] and ACI 364.1-R07 [4]

\begin{tabular}{lll}
\hline \multicolumn{1}{c}{ Characteristic } & \multicolumn{1}{c}{$\begin{array}{c}\text { Test Method or } \\
\text { Observation }\end{array}$} & \multicolumn{1}{c}{ Requirements } \\
\hline Delamination & Hammer sounding & No delamination \\
\hline Surface tensile & Pull-off test & $\geq$ adhesion $(1.5-2 \mathrm{MPa})$ \\
strength of substrate & & $=\mathrm{f}_{\mathrm{ct}}$ \\
& & $\geq 1 \mathrm{MPa}$ \\
\hline
\end{tabular}




\begin{tabular}{lll}
\hline Crack movement & $\begin{array}{l}\text { Mechanical or electrical } \\
\text { gauges }\end{array}$ & No crack movement \\
\hline Crack width and depth & $\begin{array}{l}\text { Mechanical or } \\
\text { electrical gauge, } \\
\text { Core and visual/Ultrasonic }\end{array}$ & \\
\hline Carbonation depth & $\begin{array}{l}\text { Phenolphtalein test } \\
\text { Concrete cover }\end{array}$ & < concrete cover \\
\hline Chloride content & $\begin{array}{l}\text { Site sampling and chemical } \\
\text { analysis/ }\end{array}$ & See guidelines \\
\hline Rebar corrosion & Half-cell potential mapping & See guidelines \\
\hline $\begin{array}{l}\text { Penetration/presence } \\
\text { of other contaminants }\end{array}$ & $\begin{array}{l}\text { Site sampling and chemical } \\
\text { analysis }\end{array}$ & See guidelines \\
\hline Compressive strength & $\begin{array}{l}\text { Core and crushing test } \\
\text { Rebound hammer } \\
\text { (mapping) }\end{array}$ & $\begin{array}{l}\text { Depends on structural } \\
\text { behaviour and design }\end{array}$ \\
\hline
\end{tabular}

Non-destructive techniques are also helpful, especially when large areas have to be investigated (Table 4).

Table 4 Non-destructive or semi-destructive techniques for the assessment of concrete structures [5]

\begin{tabular}{cc}
\hline In-place tests to estimate strength & Non destructive tests for integrity \\
\hline Rebound hammer & Visual inspection \\
Ultrasonic pulse velocity & Stress wave propagation methods \\
Probe penetration & Ground penetrating radar \\
Pull-out & Electrical/magnetic methods \\
Break-off & Nuclear methods \\
Maturity method & Infrared thermography \\
\hline
\end{tabular}

It is important to combine different testing methods and investigation operations. A good diagnosis hardly requires overlapping information because of the variation of site material properties and compositions. A destructive method will clearly identify a physical or chemical property, specifically where specimen has been sampled, while a non destructive method will give a general overview on the whole structure, which can be calibrated by means of results of destructive analysis.

\section{SURFACE PREPARATION}

\subsection{General considerations}

Surface preparation is one of the key issues in obtaining high-quality bonded concrete overlays. The term surface preparation is not restricted to the processes conducted immediately prior to the overlay placement. Here, surface preparation includes all processes, measures, and circumstances influencing the interface or contact surface between the substrate and the concrete overlay. Extensive research has been devoted to factors affecting the bond between substrate and overlay. In order to conduct quantitative 
comparisons, bond strength tests are necessary. A large number of test methods have been developed. They cover pure tension, shear, and various combinations of tension, compression, and shear. The predominant test method is the pull-off test on cores. One problem is that the failure may be located in the substrate, the interface, or the overlay. Also combined failures are frequent. However, if the failure is not an interface failure, the measurement is only a lower bound of the bond strength. This condition makes statistical interpretation, evaluation, and quality assurance more difficult. However, we know from numerous laboratory and field tests as well as extensive practical use of bonded concrete overlays for pavements, bridge decks, and industrial floors, that if all measures during concrete removal, cleaning, concrete placement, and curing are meticulously conducted, the bond strength developed will be sufficiently high to accommodate the stresses that may develop due to differential shrinkage and normal traffic.

There are a large number of factors that may affect bond strength, some are more important than others (Fig. 3). However, some of them are critical in the sense that one cannot compensate a poor execution in one aspect with an excellent execution in another one. The most important factors are the following five:

- absence of micro-cracking,

- absence of laitance layer,

- cleanliness,

- compacting,

- curing.

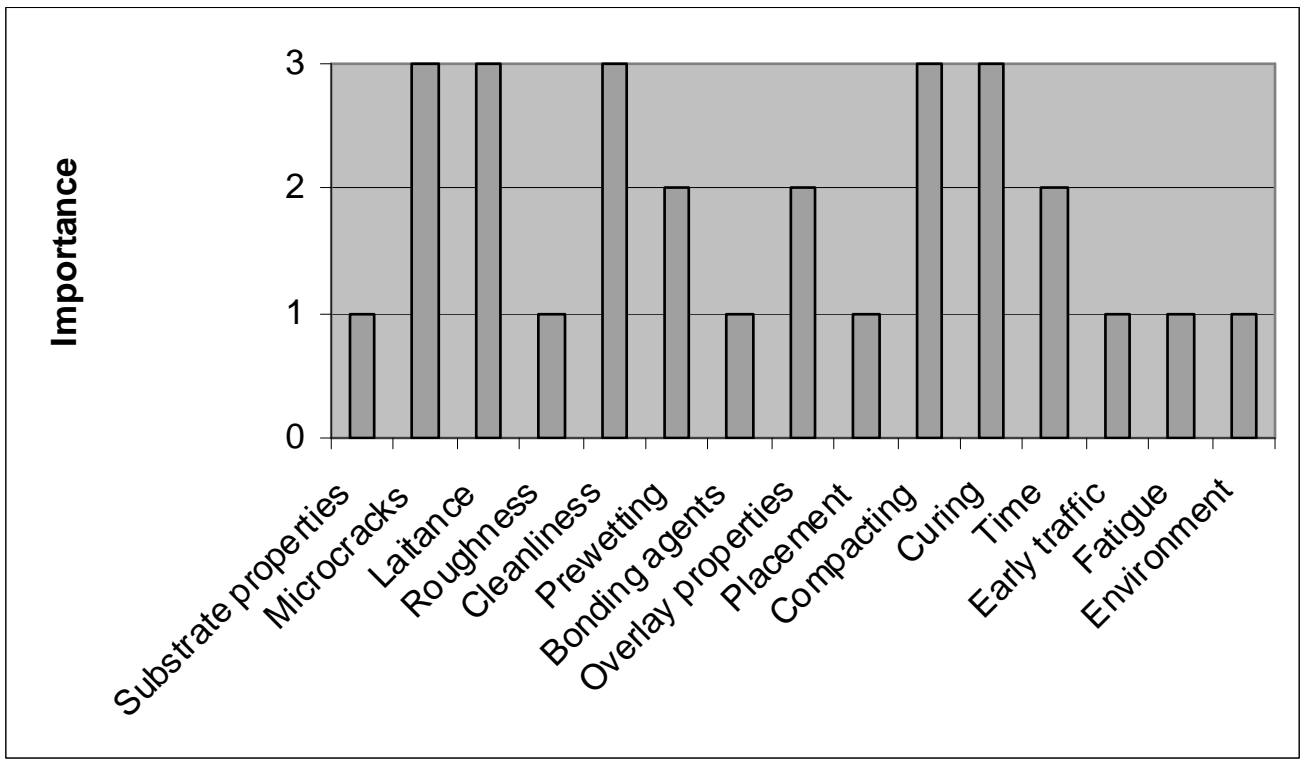

Fig. 3 - Factors affecting bond arranged chronologically and after order of importance [6]

\subsection{Integrity of the substrate}

Concrete overlays are frequently used in concrete repair. The repair process usually contains removal of deteriorated concrete. Many removal tools, e.g., milling, scarifying (SC), pneumatic hammers (J), and chipping, introduce micro-cracks into the substrate 
material. They may be efficient in removing poor concrete but what is needed is a sound and crack-free substrate to promote good bond (Fig. 4). Water-jetting (hydrodemolition) is efficient without causing micro-cracking. Besides, it is the only removal method that works selectively, i.e., removes damaged and low-quality concrete while saving the sound and high-quality concrete. If water-jetting (WJ) cannot be used due to limitations in water handling or disproportional establishment costs, the micro-cracking may be eliminated or at least limited by a combination of mechanical removal and subsequent sandblasting.

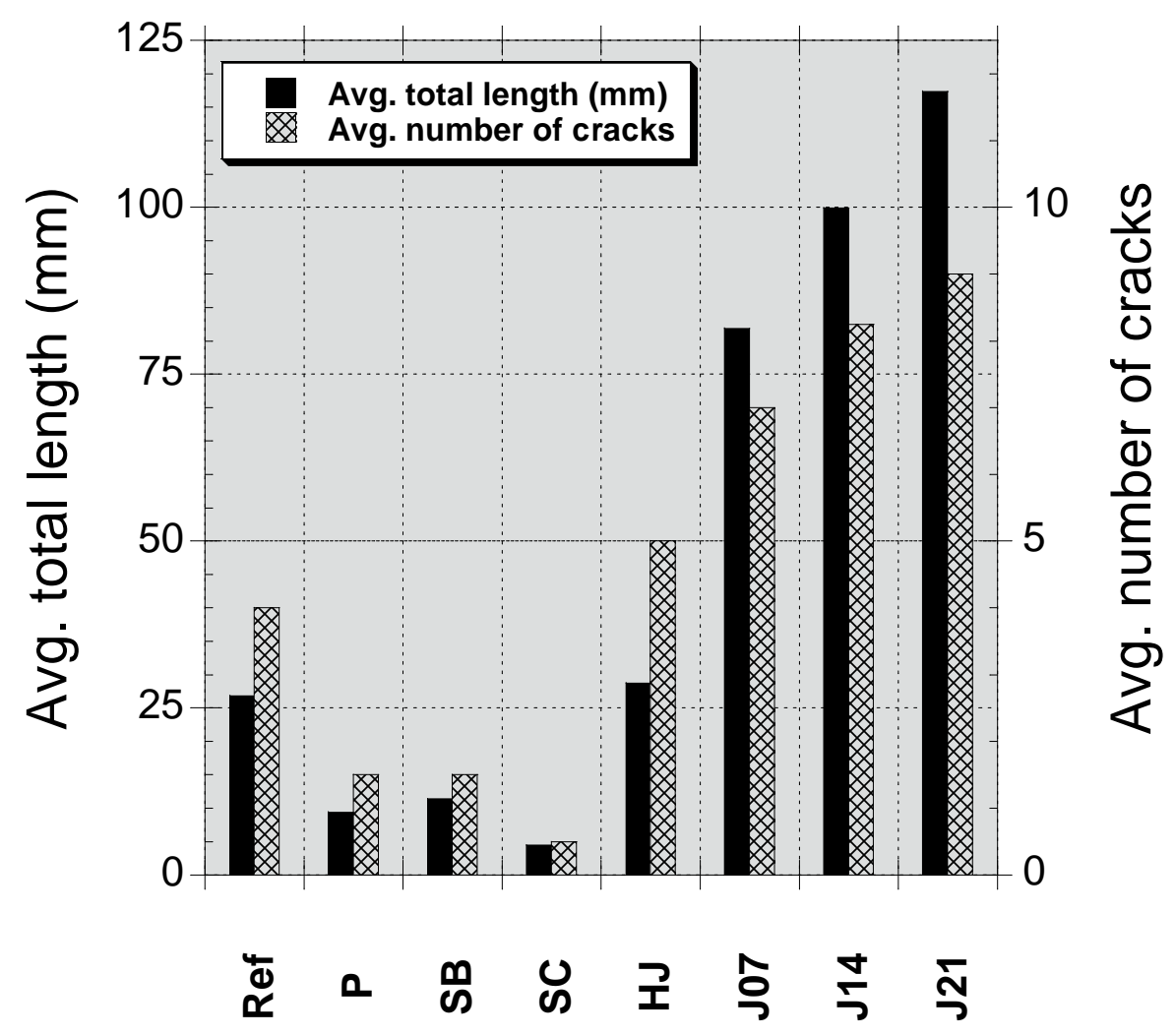

\section{Surface preparation technique}

Fig. 4 - Total crack length and number of cracks as a function of the surface preparation technique (Reffor untreated, $P$ for polished, SB for Sandblasting, SC for scarifying, HJ for Hydro-Jetting and J for Jack hammering of 7, 14 and $21 \mathrm{~kg}$, respectively) [7]

\subsection{Removal of the laitance layer}

In repairs of concrete slabs, any laitance layer is removed as a part of the deteriorated concrete. However, bonded concrete overlays may also be a part of a new concrete structure, e.g., on top of precast concrete elements. In this case, the removal of the laitance layer, i.e., the weak layer containing cement and fines and brought to the top by bleeding water, is important. 


\subsection{Cleaning of the substrate}

The cleanliness of the substrate prior to overlay placement is the single most important factor for good bond. The substrate has to be free from loose particles, dust, oil, and pollutions at the moment of concrete casting. Water-jetting provides possibilities for a very clean substrate and removes dust and corrosion products from the reinforcing steel, but has to be directly followed by a meticulous removal of loose concrete particles in order to prevent exposed unhydrated cement surfaces to bond to the saturated substrate surface. It should not be forgotten to ensure that the substrate is clean at the moment of concrete placement, pollutions from the construction traffic or environment may have ruined the cleanliness.

\subsection{Substrate surface moisture condition}

For bonded overlays it is commonly specified that the substrate surface has to be prewetted but surface-dry prior to overlay application. However, little evidence is provided in the literature suggesting that this actually improves the quality of the bond. If prewetting is done then it needs to be ensured that the substrate surface has dried out completely before the overlay is applied as any water in the substrate surface pores will prevent mechanical interlock between substrate and overlay.

\section{OVERLAY MATERIALS}

\subsection{Compatibility considerations}

Traditionnally, the design approaches for overlays and repairs in general were essentially based on the following principle: repair like with like [8]. Based on this concept, the use of a repair material with similar constituents and proportions was assumed to free the designer from performance assessment tests and guarantees repair durability.

Though the "repair like with like" approach sounds logical, even if they are identical in composition, the repair material and the original concrete cannot exhibit the same behaviour over time. For instance, when a freshly cast overlay/repair material is exposed to ambient temperature and humidity, it undergoes self-desiccation strains, drying strains and thermal strains which cannot occur freely, inducing stresses and eventually cracking in the composite system.

As first advocated in a few groundbreaking publications [8-11], the overall issue of concrete repairs must rather be addressed in terms of compatibility. In particular, dimensional compatibility of the overlay/repair material with the existing concrete substrate determines the repair's ability to resist cracking, and depends on the degree of restraint, the magnitude of shrinkage, the modulus of elasticity and the creep/relaxation characteristics, which altogether determine the material stress state, and on the tensile strength of the material [8]. This complex interplay, or race, between the tensile stresses induced by the restrained strains, the stress relief due to the creep, and the gain in strength determines 
whether or not cracking will occur. Dimensional compatibility of cement-based materials can be increased by increasing the water/cement ratio and reducing the paste-aggregate ratios [12-13]. An increase in water/cement ratio will reduce the tensile strength and hence the crack resistance of the overlay. However, in the same time it results in higher tensile relaxation and creep and a lower elastic modulus of the overlay, which reduce the tensile stresses due to restrained shrinkage. As such, the overall effect of an increasing water/cement ratio within common ranges has a positive effect on overlay cracking. Promising approaches for offsetting shrinkage impact or mitigating its intensity include the use of a shrinkage reducing admixture (SRA) or expansive cement (shrinkagecompensating concrete).

The other important compatibility issues to consider in selecting or designing a concrete overlay mixture are permeability, chemical and electrochemical compatibilities. The constituents of the material must be carefully chosen based on the condition and state of contamination of the substrate.

\subsection{Use of a bonding agent}

The use of bonding agents has been a relatively common practice intended to ensure adequate bond of overlays. Nevertheless, the body of data published over the years never led to convincing conclusions on their actual usefulness, most likely because of the compatibility problems incurred when introducing a third material in the repair composite systems. In addition, there is the possibility that the bonding agent could act as a bond breaker if allowed to dry before the placement of the concrete overlay [14]. The potential advantage of using a bonding agent does not lie in a significant increase of the average bond strength, but mostly in a more uniform and reliable bond over the surface. This is true only if the agent is placed adequately and in a timely manner, which often proves to be difficult in the field.

As a matter of fact, with the surface preparation techniques available today, the use of bonding agents is generally not required anymore to generate proper bond [14]. The importance of the quality of surface preparation operations was discussed previously. Also, the availability of vibrating placement equipment today contributes to the achievement of satisfactory bond on a more consistent basis, as vibration minimizes voids in the interface area and promotes penetration of the repair material into the substrate pores.

If bonding agents are to be used, the variety of materials available for overlay applications include cement grout and mortar, latex and other polymer materials, latex-modified grout and mortar, and epoxy resins. An important aspect to consider when selecting a bonding agent is its compatibility with the materials to bond. Although no single material used as a bonding agent has proved to consistently yield durable bond, the most conclusive results are still associated with the use of cement grout. Ideally, the grout should be sprayed onto the substrate in order to maximize the uniformity of application. Spraying should be performed on an $S S D$ surface, at a pace such that a distance of 2.5 to $3.0 \mathrm{~m}$ is kept in front of the overlay material placement. The fresh bonding agent layer should be broomed to prevent accumulations in low points of the surface. Drying of the slurry before it is overlaid 
must be prevented, as it will likely affect bond significantly. If its color becomes lighter, a slight amount should be added before overlaying. In areas where it has started hardening, it should be removed (through scabbling or sandblasting) and reapplied.

\subsection{Typical recommendations / requirements for overlay materials}

A variety of concrete mixtures can be used for slab and pavement overlay applications. Nevertheless, while polymer-modified concretes are often used for bridge deck overlays, slab and pavement overlay mixtures are most generally from either one of the following categories: plain cement concrete, fast-setting ("fast-track" concrete) or fiber-reinforced concrete. General indications on slab and pavement overlaying materials provided by the American Concrete Pavement Association (ACPA) [14] and the American Concrete Institute committee 325 [15] are summarized hereafter.

\section{ACPA recommendations}

In its guide on bonded overlays, the American Concrete Pavement Association [14] gives the designer much latitude in the concrete mixture selection, pointing out that in most situations plain concrete mixtures are adequate and, when necessary (quick reopening to traffic), fast-setting repair mixtures with high initial resistance can be used. Such "fasttrack" mixtures have been used successfully in a number of applications.

As in most applications, mixture designs and selection of constituents depend on both the characteristic and performance requirements. Examples of typical plain and fast-track mixtures in the guide are given in Table 5.

Table 5 - Typical mixtures for fast-track concrete overlays (from ACPA, 1990 [14])

\begin{tabular}{lll}
\hline Components/characteristics & Plain concrete & Fast-track concrete \\
\hline Cement Type I & $270 \mathrm{~kg}$ & \\
Cement Type III & & $322 \mathrm{~kg}$ \\
& & $\left(\right.$ or $290 \mathrm{~kg}$ Type III $+32 \mathrm{~kg}$ P.F.A. $\left.{ }^{1}\right)$ \\
Coarse aggregate $\left(19 \mathrm{~mm} \leq \mathrm{d}_{\max } \leq 25 \mathrm{~mm}\right)$ & $684 \mathrm{~kg}$ & $641 \mathrm{~kg}$ \\
Fine aggregate & $684 \mathrm{~kg}$ & $641 \mathrm{~kg}$ \\
Water-to-cement ratio & $\leq 0.45$ & 0.425 \\
Water reducing agent & yes & Yes \\
Air-entraining agent (air content: $6 \pm 1.5 \%)$ & yes & Yes \\
\hline${ }^{1}$ P.F.A.: pulverized fuel ash & &
\end{tabular}

ACI C325 committee recommendations on pavement overlays 
With respect to the choice of overlay materials, the ACI committee 325 guide on concrete pavement overlays discusses in general the characteristics to be considered among the main families of materials used: plain cement concrete, fast-track and fiber-reinforced concrete. These characteristics are presented in Table 6.

First, the guide emphasizes that overlay concrete mixtures typically have constituents and proportions similar to those used for conventional concrete pavements. In view of minimizing shrinkage and shrinkage cracking, it is recommended to minimize the total amount of water and maximizing the volumetric proportion of aggregate in the mixtures, which is in line with the previous recommendations for dimensional compatibility.

In order to control cracking of the overlay and to increase its toughness, fiber reinforced concrete can be very effective. In some cases, the slab flexural strength may also be increased [15]. A wide variety of fiber materials can be used to reinforce concrete, such as steel, polypropylene, polyester, and polyolefin fibers.

Table 6 - ACI C325 recommendations for plain concrete mixes used for bonded overlays (from ACI C325, 2006 [15])

\section{Components / characteristics}

Binders

Aggregates

Commonly used
admixtures

Water/binding ratio

Fibers

Typical mixtures

Fast-track mixtures

\section{Recommendation}

-Type I, II; Type III for high early strength (ASTM C 150)

-Fly ash (type $\mathrm{C}$ or F)

-good quality aggregates, non-reactive

-common max. coarse aggregate size: 19 to $25 \mathrm{~mm}$

-larger max. sizes considered by some agencies

-lower max. size for thinner overlays

-largest and most practical maximum coarse aggregate size should be used to minimize paste content, reduce shrinkage, minimize costs, and improve mechanical interlock properties at joints and cracks

$-\mathrm{d}_{\max } \leq\left(\mathrm{h}_{\text {overlay }} / 3\right)$

-air-entraining agent

-accelerator (non-chloride if steel reinforcement is present)

- water reducer

$-\mathrm{W} / \mathrm{B} \leq 0.45$ (humidity $\&$ freeze / thaw conditions)

-lower W/B ratios recommended for thin overlays

-steel, polypropylene, polyester, and polyolefin fibers

-cement: $295-415 \mathrm{~kg} / \mathrm{m}^{3}$ (sometimes more in fast-track)

-air content: 4 - $6 \%$

$-\mathrm{f}_{\mathrm{c} 28-\mathrm{d}} \geq 28 \mathrm{MPa}$

$-\mathrm{MOR}_{28-\mathrm{d}} \geq 4.5 \mathrm{MPa}$

-cement $\geq 385 \mathrm{~kg} / \mathrm{m}^{3}$ 
-Type III cement, rapid-setting cement or set-accelerating admixture

$-\mathrm{W} / \mathrm{B} \leq 0.43$

Bonding agent

-no bonding agent required according to many specialists

-many agencies specify the use of a cement grout

$(\mathrm{W} / \mathrm{B} \leq 0.62(\mathrm{ACPA}, 1990))$

Essentially, in addition to the basic characteristics of slab and pavement concrete, overlay concrete mixtures for these elements must be designed in view of meeting the different compatibility requirements.

\section{DESIGN OF OVERLAYS}

The design of Bonded Concrete Overlays (BCO) is presented following two approaches: the overlay design for sufficient strength and the design to prevent debonding of the overlay.

\subsection{Design for Sufficient Strength}

The design for sufficient strength of a BCO determines the thickness of the overlay, assuming a perfect bond between the overlay and the substrate. Thus, the design procedures are similar to those of monolithic structures. Depending on the design method, the procedure may include the evaluation of the structure to be overlaid and of its contribution to the strength in the final overlaid structure. It is recommended to choose a method that utilizes an evaluation of the current conditions of the existing pavement, i.e. materials characterization, to assess the structural contribution of the existing pavement and to take it into consideration for the BCO thickness design.

There is not an absolute solution to BCO thickness design. The extremes of the spectrum of design methodologies feature the mechanistic approach, on one side, and the empirical approach on the other. The development of research has enabled the advancement of mechanistic methods.

If the purpose of the $\mathrm{BCO}$ is to remedy structural deficiencies, the design is based on the following equation, by which the $\mathrm{BCO}$ is designed by determining the additional thickness of concrete needed to carry the anticipated traffic:

$D_{B C O}=D_{f}-D$

where $D_{\mathrm{BCO}}$ is the overlay thickness, $\mathrm{D}_{\mathrm{f}}$ is the required thickness to carry the future traffic if the pavement were constructed new, and $\mathrm{D}$ is the effective existing pavement slab thickness. The design methods vary in the way in which the existing pavement contribution $\mathrm{D}_{\mathrm{f}}$ is determined and the way the original thickness is affected by the pavement condition. Common design methods, which all are based on this concept, are the AASHTO, the Corps of Engineers, and the Portland Cement Association procedures.

The recommended design procedure is to follow the AASHTO method, which is a combination of a mechanistic and an empirical procedure. 


\subsection{Design for Durable Bond}

Maintaining a strong bond between the overlay and the substrate should be a foremost goal in the design of the BCO; if the BCO remains monolithic with the substrate, it will be able to carry the loads for which it is designed. The measurement of a certain value of bond strength is an indication that the overlay can attain and maintain its bond with the substrate. The recommended values for bond strength may vary regarding country and specific situation:

\section{USA}

The United States' recommendation is issued from the American Concrete Pavement Association: shear bond strength of 200 pound per square inch (psi) is sufficient to withstand shearing forces and ensure bond is maintained. This value is equivalent to shear strength equal to $1.4 \mathrm{MPa}$.

\section{Europe}

The EN 1504 European Standard specifies a requirement of 2.0 MPa for tensile bond strength for structural applications, and 1.5 MPa for non-structural applications.

\section{Japan}

Japanese guidelines recommend a minimum overlay thickness of $50 \mathrm{~mm}$ and tensile bond strength of 1.0 MPa between overlay and substrate.

\section{Sweden}

The Swedish National Road Administration established a requirement of $1.0 \mathrm{MPa}$ for tensile bond strength.

Although achieving sufficiently high initial bond strength is desirable, it is important to stress that it is not a guarantee of bond durability. Strong early adhesion can decrease over time due to compatibility shortcomings, as discussed earlier.

\subsection{BCO Reinforcement Design}

The purpose of the steel reinforcement is to hold cracked concrete together and to maintain load transfer; it does not increase the pavement structural capacity. It is recommended that the $\mathrm{BCO}$ be reinforced in a similar fashion as the existing pavement, i.e., similar steel percentage, bar sizes and spacing, unless there is a significant deficiency in the original pavement reinforcement design.

\section{CONSTRUCTION PROCEDURE AND QUALITY ASSURANCE}

This chapter reviews observations of good practices and quality control/quality assurance in the implementation of projects involving cement-based bonded overlays.

\subsection{Substrate Surface Preparation}

One of the requirements of the composite overlay systems is the ability to perform as a whole, as an integrated monolithic system. This can be achieved only by providing an adequate bond between the existing concrete and overlay. The bond must be durable and long lasting. The durability in this context may be defined as lasting interfacial coexistence of two materials combined in a composite system. 
When overlay projects are not successful, the overlay material itself is often blamed for "not sticking", but the real source of trouble commonly lies with the surface preparation. The importance of surface preparation cannot be overstated. Proper attention to surface preparation is essential for a durable repair. Regardless of the cost, complexity and quality of the repair material and application method selected, the care with which deteriorated concrete is removed and concrete reinforcement surface are prepared will often determine whether a repair project will be successful.

The process of preparation for repair is the process by which sound, clean and suitably roughened surfaces are produced on concrete substrates. This process includes the removal of unsound and, if necessary, sound concrete and bond inhibiting foreign materials from the concrete and reinforcement surfaces, opening the concrete pore structure, as well as reinforcement damage verification and repair, if necessary.

Removal tasks have to be performed in a manner that ensures that the remaining concrete and reinforcing steel retains its structural integrity. Equipment used to perform the work must not overload the structure, and care must be taken to remove only so much concrete that the member being repaired or rehabilitated is not critically weakened. Any impact forces needs to remove damaged concrete and minimizes damage to the bond between the remaining concrete and steel. Methods to remove rust and chlorides from the steel should also minimize damage and loss to the remaining steel.

\subsection{Pre-Overlay Repairs}

Surface preparation for overlays shall include the pre-overlay repair of defects such as deterioration, corrosion of reinforcement, honeycombed areas, delaminations, small and large holes, sharp protrusions, and cracks. Pre-overlay repair shall consist of all the repair procedures required to bring the substrate to a condition suitable for overlay.

\subsection{Concrete Removal Operation}

The concrete removal process leaves the resulting surface with varying degrees of microcracks and fractures, commonly referred to as "bruising." Bruising creates a zone of weakness that will affect the bond of the repair material to the substrate. Removal subjects the concrete substrate to a wide range of dynamic loads and the resulting bruising will depend on the method used and the quality of the concrete. The depth of the bruised layer varies, but is typically on the order of $3 \mathrm{~mm}$.

\subsection{Reinforcement Corrosion Protection}

Prior to overlay application, the corrosion of reinforcement in substrates must be addressed. The overlay is not going to mitigate active corrosion process; on the contrary, it may accelerate it.

When epoxy-coated steel reinforcement is exposed in the repair area, it should be recoated with an epoxy coating. Special care must be exercised in recoating operations to achieve defect-free full surface coverage. Uncoated spots may result in severe corrosion in repair areas. When uncoated reinforcing steel is exposed in the repair area, application of a protective coating should not be done, because it may cause corrosion in areas immediately adjacent to a repair. 


\subsection{Moisture Conditioning of the Substrate}

The moisture condition of the substrate will determine the rate of movement of water from the repair mortar to substrate concrete due to the moisture imbalance between the two layers. Both the surface moisture condition and the moisture distribution inside the substrate are important. During the process of water movement, two things will occur: penetration of water from the repair mortar in the capillaries of substrate concrete, and hydration of cement paste in the repair.

The optimum moisture condition will vary from substrate to substrate in otherwise equal conditions because the performance of the bond depends on the way the substrate will affect the direction and rate of water movement between phases of the composite repair system.

\subsection{Materials Selection}

The concrete should be selected to provide suitable bond and good compatibility with the substrate, and to meet durability and strength requirements. Supplementary cementing materials, such as fly ash or granulated slag, may be used to reduce heat of hydration and to reduce costs. The water-cement ratio should be as small as possible. Aggregates should be selected for workability and should be durable. Using improved aggregate gradation can result in reduced paste requirements. Admixtures can include air entraining agents, moderate or high range water reducers; accelerators for cold weather; and retarders for hot weathers.

Steel reinforcing and steel and synthetic fibers can be used for reinforcement. Steel reinforcement has been used in the form of tied bars and welded mats. Steel fibers have been used successfully to control cracks and to minimize drying shrinkage cracking. Synthetic fibers have been used to control shrinkage cracking.

\subsection{Joints}

Jointed slabs and pavements require that the joints be reinstated in the original slab, and the joints should be maintained in the overlay. Sawing the joints followed by application of suitable high elongation joint filler may be the best solution. Joints in structural slabs and decks are usually expansion joints. The overlays must be constructed to maintain the expansion required and to insure a durable joint.

\subsection{Application procedures}

Experience has repeatedly demonstrated that no step in overlay application can be omitted or carelessly performed without detriment to the durability. Inadequate workmanship, procedures, or materials result in inferior overlays, which will prematurely fail.

Adequate placement capacity should be provided so that material can be kept workable and free of cold joints during the placement. The placement process and equipment should be arranged to deliver the material to its final position without segregation. The equipment should be adequately and properly arranged so that placing can proceed without undue delays and manpower should be sufficient to ensure the proper and timely placing, consolidating, finishing and curing of the repairs. 
To obtain a durable overlay surface, proper procedures should be carefully followed. The compaction is important to obtain a dense and homogeneous overlay as well as a good and uniform bond. Especially, the compaction is important in overlays on rough surfaces to prevent the development of air pockets in the valleys of the surface texture. The use of vibration pokers and vibration platforms is recommended. Recent studies show that good result may be obtained with self-compacting concrete as well. Following consolidation, the operations of screeding, floating, and troweling should be performed in such a manner that the overlay material will be worked and manipulated as little as possible to produce the desired result.

Over-manipulation of the concrete brings excessive fines and water to the surface, which lessens the quality of the finished surface, causing checking, crazing, and dusting.

\subsection{Curing}

Good curing is vital to producing an overlay with satisfactory performance. Good curing not only increases durability and wear resistance, but reduces early drying, shrinkage and cracking. Curing must be started early. Proper curing is even more important for overlays than for ordinary concrete because of the potential for rapid early drying of the relatively thin repair since they have large surface areas in relation to their volumes and moisture can be lost quickly.

\subsection{Quality Control}

Quality control is the establishment of a proper level of quality required for a given project, and controlling of all operations to a degree that will assure that the required level will be attained. Quality control cannot be attained, however, without high quality project specifications, which constitute the first and very critical step in quality control. Therefore, the specifications must be a high quality engineering document, and the goal of the quality control/quality assurance is to assure that all requirements specified are fulfilled.

At the present time, practical answers to the problems of bond may depend only on a short-term bond strength testing rather than long-term performance. An initially achieved adequate bond is only an indication of conformance with the specified parameters. There is no well-defined relationship between initial bond strength and the longevity of an overlay. Longevity is influenced by many factors, including substrate surface preparation and texture, dimensional stability of the overlay material, and substrate surface conditions.

Although most of the specified requirements and engineers tend to focus on the achievement of the prescribed initial bond strength, it must be realized that although important, this parameter is not as important and critical as the bond durability - the lasting interfacial coexistence of two materials - as dictated mainly by the surface conditions of the overlayed structure and the dimensional compatibility between substrate and overlay.

\section{MAINTENANCE AND REPAIR OF MATERIALS}

\subsection{Types and Causes of Distresses}


Bonded concrete overlays sometimes exhibit distress and require repair. The most common types of distress are:

1. cracking,

2. delamination,

3. spalling.

Cracking often leads to delamination since the stresses due to differential expansion and contraction are the highest at boundaries. Delamination also is caused by inadequate surface preparation, surface contamination, or premature curing of some bonding agents that serve as bond breakers. Spalling can occur at joints due to improper construction or inadequate or non-maintained joint filler and to inadequate curing, expansive aggregate or corrosion of reinforcing steel.

\subsection{Evaluation of Damage}

It is important to determine the extent and cause of damage. The condition survey should:

1. map the location of cracks,

2. locate the extent of delamination,

3. map the location of spalls and any other distresses.

\subsection{Repair Methods}

When delamination has not occurred, non-moving cracks can be repaired by epoxy injection or a topically applied monomer or epoxy system especially formulated for crack repair. Epoxy injection provides the best structural repair but the topically applied materials are much less expensive to apply and more practical for extensive cracking in the overlay. Moving cracks, which occur in bonded concrete overlays at joints in the substrates, should be applied with an elastomeric joint material that can accommodate the expected joint movement.

Delaminated overlays are repaired either by removing and replacing or by rebonding the overlay to the substrate. Rebonding can be accomplished by injecting epoxy through holes drilled in the overlay at regular intervals or by using mechanical connectors such as steel rods epoxied into drilled holes into the substrate.

Removing and replacing the overlay may be the least expensive and most effective method of repair. The cause of the distress should be determined before making a repair decision. If replacement is the method selected, the construction of the replacement overlay should follow the procedures for new overlays.

The cause of spalling should be determined prior to repair. The damaged concrete should be carefully removed in accordance with recognized repair procedures. For small repairs, latex-modified mortar or polymer mortar may be the best materials. For large repairs, latex-modified concrete, polymer concrete, or Portland cement concrete made with small aggregate is preferred.

\section{CONCLUSIONS}

This document provided a summary of the various aspects to address in design, construction and maintenance of an overlaid concrete slab or pavement. In addition to the basic considerations involved in the construction of new slabs or pavements there are some very specific and crucial issues to be addressed in any overlay project, in particular: 
- Proper assessment of the existing structure;

- Adequate surface preparation;

- Selection of material(s) in view of satisfying the various compatibility requirements (dimensional, permeability, chemical and electrochemical);

- Design with proper account made of existing condition and service loads.

Experience shows that when implemented in accordance with the recommendations summarized in the present document, bonded overlays are generally the most economical alternative when significant life extension of slabs and pavements is sought.

\section{REFERENCES}

[1] Bonded cement-based material overlays for the repair, the lining or the strengthening of slabs and pavements. B. Bissonnette, L. Courard, D. Fowler and J.L. Granju. RILEM STAR Report Volume 3, 193-RLS RILEM TC (Springer, eds), Dordrecht, 2011, 175p.

[2] Vaysburd, A. M., \& Emmons, P.H., "How to make today's repairs durable for tomorrow - corrosion protection in concrete repair", Construction and Building Materials, 14 (4), 2000, pp. 189-197.

[3] EN 1504-10. Products and systems for the protection and repair of concrete structures - Definitions - Requirements - Quality control and evaluation of conformity, CEN, Brussels.

[4] ACI 364.1-R07 (2007) Guide for Evaluation of Concrete Structures before Rehabilitation, Committee 364 Rehabilitation, American Concrete Institute, Detroit (MI), USA, 22 p.

[5] Carino, N.J. (2003) "Non destructive test methods to evaluate concrete structures". Sixth CANMET/ACI International Conference on the Durability of Concrete, Special Seminar, Thessaloniki, Greece, 75 p.

[6] Silfwerbrand, J., \& Beushausen, H., (2005)"Bonded Concrete Overlays - Bond Strength Issues". Proceedings, International Conference on Concrete Repair, Rehabilitation and Retrofitting. Cape Town, South Africa, November 21-23, 2005, pp. 19-21. (Extended version on conference CD, 10 pp.)

[7] Concrete removal techniques: influence on residual cracking and bond strength. B. Bissonnette, L. Courard, A. Vaysburd and N. Bélair. Concrete International, 28(12) 2006, 49-55.

[8] Emmons, P.H., Vaysburd, A.M. (1993) Compatibility considerations for durable concrete repairs, Transportation Research Record 1382, pp. 13-19.

[9] Emberson, N.K., Mays, G.C., (1990) Significance of property mismatch in the patch repair of structural concrete - Part 1: Properties of repair systems, Magazine of Concrete Research, 42(152), pp. 147-160.

[10] Pigeon, M., Saucier, F. (1992) Durability of Repaired Concrete Structures, Advances in Concrete Technology (édité par V.M. Malhotra), Compte-rendus de conférence, Athènes, Grèce, pp. 741-773. 
[11] Bissonnette, B. (1996) Le fluage en traction: un aspect important de la problématique des réparations minces en béton, Thèse de doctorat, Université Laval, Québec (QC), Canada, 290 p.

[12] Pigeon, M. et Bissonnette, B. (1999) Tensile creep and cracking potential of bonded concrete repairs, Concrete International, 21(11), novembre, pp. 31-35.

[13] Bissonnette, B., Boily, D., Bastien, J., Fafard, M. (2001) Tensile creep of concrete repair materials: recent experimental findings towards optimization, RILEM $6^{\text {th }}$ International Conference on Creep, Shrinkage \& Durability Mechanics of Concrete and Other Quasi-Brittle Materials, Boston (MA), USA, 20-22 août, pp. 599-604.

[14] ACPA (1990) Guidelines for Bonded Concrete Overlays, Technical Bulletin TB-007P, American Concrete Pavement Association, Arlington Heights, (IL), USA, $15 \mathrm{p}$.

[15] ACI 325.13-R06 (2006) Concrete Overlays for Pavement Rehabilitation, Committee 325 Pavements, American Concrete Institute, Detroit (MI), USA, 39 p. 